\title{
Bulanık CODAS Yöntemi ile Kripto Para Yatırım Alternatiflerinin Değerlendirilmesi
}

\section{Evaluation of Cryptocurrency Investment Alternatives with Fuzzy CODAS Method}

\author{
Ali KATRANCI ${ }^{\left(D^{1}\right.}$, Doç. Dr. Nilsen KUNDAKCI ${ }^{(D)}$
}

\begin{abstract}
$\ddot{O} z$
Geçmişten bugüne kadar insanlar, ihtiyaçlarını karşılamak için çeşitli ticari işlemler gerçekleştirmişlerdir. Üretilen fazla malların değiş tokuşu ile başlayan bu ticari işlemler, ilerleyen dönemlerde çeşitli değerli eşyalar ve çeşitli formlardaki paralar ile gerçekleşmiştir. Çeşitli formlarda kullanılan paralar zaman içinde günümüzdeki kullandığımız biçimdeki gibi kâğıt formuna gelmiş ve ticari işlemler bu şekilde devam etmiştir. Günümüzde ise teknolojinin gelişmesi ile ticaret, internet üzerinden yaygın bir şekilde devam etmektedir. Özellikle internetin gelişmesi ile kripto para olarak adlandırılan, fiziksel varlığı olmayan ve tamamen internet üzerinde kullanılan paralar popüler hale gelmiştir. Kripto paraların günümüzde ticari işlemlerin yapılması, çeşitli ödemelerin gerçekleştirilmesi, alışveriş gibi alanlarda kullanımı giderek artmaktadır. Çeşitli ticari işlemlerin yanı sıra, kripto paraların henüz gelişimini tamamlaması, kullanımının giderek artması ve gelecekte daha da değerli hale gelecek olması gibi nedenlerle yatırım amacıyla kripto para satın alanların sayısı giderek artmaktadır. Bu çalışmada, yatırım yapmak amacıyla belirlenen en uygun on kripto para alternatifi Çok Kriterli Karar Verme (ÇKKV) yöntemlerinden bulanık CODAS (COmbinative Distance-based ASsessment) yöntemi ile değerlendirilmiştir. Bulanık CODAS yaklaşımında kullanılmak üzere coin ekibi/geliştiriciler, yıllık ortalama getiri, toplam piyasa değeri, roadmap, whitepaper, güvenlik, işlem hızı, destekleyen kurum ve kuruluşlar, en yüksek değerden değişim ve işlem gördüğü borsa sayısı kriterleri kullanılmıştır. Çalışmanın sonucunda yatırımcılar için en uygun kripto para alternatifi belirlenmiştir.
\end{abstract}

Anahtar Kelimeler: Kripto para, çok kriterli karar verme, bulanık mantık, bulanık CODAS

Makale Türü: Araştırma

\begin{abstract}
People from the past to the present, has carried out various commercial transactions to meet their needs. These commercial transactions, which started with the exchange of surplus goods, were realized in the following periods with various valuables and coins of various forms. The coins used in various forms became paper forms in the same way as we used today, and commercial transactions continued in this way. Nowadays, with the development of technology, commerce continues to be widespread over the internet. Especially with the development of the internet, the money, which is called crypto currency, does not have a physical presence, and is used completely on the internet, has become popular. Nowadays, commercial transactions, various payments and shopping with cryptocurrencies are increasing. In addition to various commercial transactions, the number of purchasers for the purpose of investment has been increasing since the crypto currency has completed its development and will become more valuable in the future. In this study, most suitable ten cryptocurrency alternatives identified as a means of investment have been assessed by using Fuzzy CODAS (COmbinative Distance-based ASsessment) method which is one of the MultiCriteria Decision-Making Methods (MCDM). In fuzzy CODAS method; cryptocurrency alternatives have been evaluated under the criteria of coin team / developers, annual average return, total market value, roadmap, whitepaper, security, transaction speed, supporting institutions and organizations, the highest
\end{abstract}

\footnotetext{
${ }^{1}$ Pamukkale Üniversitesi, Sosyal Bilimler Enstitüsü, akatrancii @ gmail.com.

${ }^{2}$ Pamukkale Üniversitesi, İktisadi ve İdari Bilimler Fakültesi, nilsenk @ pau.edu.tr.
}

Atıf için (to cite): Katrancı, A. ve Kundakc1, N. (2020). Bulanık CODAS yöntemi ile kripto para yatirim alternatiflerinin değerlendirilmesi. Afyon Kocatepe Üniversitesi Sosyal Bilimler Dergisi, 22(4), 958-973. 
value of the exchange and the number of exchanges traded. As a result of the study, the most suitable crypto currency alternative has been determined for the investors.

Keywords: Cryptocurrency, multi-criteria decision-making, fuzzy logic, fuzzy CODAS

Paper Type: Research

\section{Giriş}

İnsanların ihtiyaçlarını karşılama amacına yönelik yaptıkları ticari işlemler tarih serüveni içerisinde değişimlere uğramıştır. Bu serüven içerisinde, ticari işlemlerde kullanılan yöntemler farklılaşmış ve bilgisayar teknolojisi sayesinde kripto paralar ticari piyasada adından söz ettirmeye başlamıştır (Alkış, 2018, s. 70). Günümüzde kullanımı giderek artan kripto paraların, ticari işlemlerden kişisel harcamalara kadar birçok alanda kullanılmasının yanında, yatırım aracı olarak da popülariteleri her geçen gün artmaktadır. Yatırım alternatifi olarak, küçük ya da büyük, tecrübeli ya da tecrübesiz her türlü yatırıcımlar için güvenli ve popüler borsalarla rekabet edebilme yeteneğine sahip olmasından dolayı güvenli bir liman olarak görülmektedir (Polat ve Akbiyık, 2019, s. 444).

2008 y1lında Satoshi Nakamato tarafindan yayımlanan "Bitcoin: A Peer-to Peer Electronic Cash System" isimli makale ile "Bitcoin, herhangi bir üçüncü kişinin aracılık ihtiyacı olmadan işlem yapılabilmesine imkân veren bir sistemdir" olarak tanımlanmıştır (Nakamato, 2008, s. 26). Daha sonraki yıllarda ise çeşitli kripto paralar piyasalarda alınıp satılsa da kripto paraların ilki ve en çok işlem yapılanı Bitcoin'dir.

Kripto para birimleri ile ilgili literatürde özellikle son yıllarda yapılan çeşitli çalışmalar mevcuttur. Kristoufek (2013), Bitcoin, Google Trends ve Wikipedia arasındaki ilişkiyi incelemiş ve farklılıkları ortaya koymuştur. Atik vd. (2015), Grander nedensellik analizi ile 2009-2015 yı1ları arasındaki Bitcoin kur fiyatlarıyla dünyada en çok kullanılan çapraz kur fiyatları arasındaki etkileşimi test etmiştir. Ram vd. (2016), Bitcoin muhasebesini hesap verebilirlik, neoliberalizm ve uygunluk çözümlemesi ile değerlendirmişlerdir. Lim ve Masih (2017), MGARCH-DCC, CWT ve MODWT yöntemlerinden yararlanarak İslami perspektif ile oluşturulan hisse senet endeksi ve Bitcoin arasındaki ilişkiyi incelemişlerdir. Chuen vd. (2018), geleneksel yatırım araçları ile kripto paralar arasındaki ilişkiyi incelemişlerdir. Şahin ve Özkan (2018), asimetrik volatilitenin belirlenmesi amaciyla ARCH, GARCH, ARCHM, EGARCH ve TARCH modellerini kullanarak Bitcoin/Amerikan Doları kuru kapanış fiyatlarından Bitcoin'e ilişkin getirileri hesaplamışlarıdır. Yıldırım (2018), Bitcoin ile altın arasındaki ilişkiyi ADF Birim Kök Testleri, Johansen Koentegrasyon Testi, Düzeltilmiş En Küçük Kareler Modeli ve Hata Düzeltme Modeli kullanarak değerlendirmiştir. Aslan vd. (2018), Bitcoin'e ait Türk Lirası cinsinden fiyat değerlerinin çeşitli dereceden eğri ve yapay zekâ tekniklerinden olan polinomsal eğri uydurma ve ANFIS yöntemleri ile tahminlemesini gerçekleştirmişlerdir. Ceylan vd. (2018), kripto para birimlerinden olan Bitcoin ve Etherium'da spekülatif balonların varlığını tespit etmiş ve ne zaman oluştuklarını tahminlemişlerdir. Genç vd. (2018), piyasadaki ilk on kripto parayı çeşitli kriterlere göre Analitik Hiyerarşi Prosesi yöntemi ile değerlendirmişlerdir.

Bu çalışmada, altın, döviz, bono vb. yatırım araçlarının dışında internetin gelişmesi ile ortaya çıkan kripto para alternatifleri değerlendirilmiş ve yatırımcılar açısından en uygun olanı belirlenmiştir. Çalışmada, literatürde az sayıda çalışma yapılmış olan bulanık CODAS yöntemi kullanılmıştır. Özellikle, Türkçe literatürde bulanık CODAS yöntemini uygulayan çalışmaya rastlanmamıştır. Ayrıca, bulanık CODAS yöntemini ele alan çalışmalarda yamuk bulanık sayılar kullanılmıştır. Bu çalışmada ise, hesaplama kolaylığı açısından üçgen bulanık sayılar tercih edilmiştir. Bunların yanında, kripto paraların bulanık ÇKKV yöntemlerinden biri ile değerlendirilmesi açısından da çalışma özgünlük taşımaktadır.

$\mathrm{Bu}$ çalışma dört bölümden oluşmaktadır. Birinci bölümde, kullanımı giderek artan kripto para kavramı tanımlanarak, kripto paraların özellikleri, yatırımcılar için alternatif kripto paralar 
ve dünya üzerinde yer alan kripto para borsaları tanımlanmıştır. İkinci bölümde, kesin değerler yerine yaklaşık değerleri kullanan bulanık mantık kavramına, bulanık küme teorisine ve bulanık sayılara değinilmiştir. Üçüncü bölümde, bulanık CODAS yöntemi açılanarak yöntemin adımlarına yer verilmiştir. Çalışmanın dördüncü bölümünde ise, yatırım alternatifi kripto paralar bulanık CODAS yöntemi ile değerlendirilerek yatırımcılara öneride bulunulmuştur. Sonuç bölümünde ise uygulamada elde edilen sonuçlara değinilerek, gelecek çalışmalar için önerilere yer verilmiştir.

\section{Kripto Paralar}

Cyripto ve currency kelimelerinin birleşmesinden oluşan, Türkçe anlamı şifreli para olan kripto paralar (Turan, 2018, s. 2) üzerinde, kripto para borsalarının henüz gelişimini tamamlamamış olması ve gerekli hukuksal düzenlemelerin yapılmamasından dolayı henüz uzlaşılmış bir tanım bulunmamaktadır (Durdu, 2018, s. 11). Kripto para; kriptografik temeline dayalı olarak, yatırımcılara güvenli işlem yapmaya imkân tanıyan ve ek sanal para arzına olanak sağlayan dijital değerlerdir (Çarkacıoğlu, 2016, s. 8). Bir başka tanıma göre kripto paralar; parasal birimlerin oluşturulmasını kontrol etmek ve fonların transferini doğrulamak için şifreleme teknikleri kullanarak blok-zincir ağında elektronik olarak oluşturulmuş ve depolanmış bir değişim aracı şeklinde tanımlanabilir (Akcan, 2018, s. 5).

Hiç şüphesiz kripto para denildiğinde akla ilk gelen Bitcoin (BTC)'dir. Ancak dünya genelinde Ethereum (ETH), Ripple (XRP), Litecoin (LTC), EOS (EOS), Bitcoin Cash (BCH), Ontology (ONT), CeChain (VET), Stellar (XLM) gibi çok bilinen kripto paralar yanında nispeten yeni sayllabilecek Libra, Ravencoin (RVM), Electroneum (ETN), WaykiChain (WICC), CelerNetwork (CELR), TomoChain (TOMO), Fetch.Al (FET), Lisk (LSK), Zcash (ZEC), Cube (AUTO), DigitalNote (XDN), V-ID (VIDT), smARTOFGIVING (AOG), Merculet (MVP) gibi çok sayıda kripto para bulunmaktadır (https://coinmarketcap.com).

\subsection{Kripto Paraların Avantajları ve Dezavantajları}

Eşler arası bağlantı (P2P-peer to peer) teknolojisini merkezi bir otoriteye bağlı olmaksızın kullanan (Ateş, 2016: 354) kripto paraların birçok avantajı ve bunun yanında dezavantajı vardır. Kripto paraların avantajları şu şekilde sıralanabilir (Tüfek, 2017, s. 78):

- Vergi, beyan ya da kayıt gibi kanuni yaptırımlardan uzaktır.

- Devletler söz konusu kripto paralar üzerinden herhangi bir vergi kesintisi uygulayamazlar.

- Kripto paralar kriptografik temellerin kullanıldığı şifreli paralardır ve bu paralarda gizlilik önemlidir.

- Kimsenin parası ve transferi kendi istemediği sürece üçüncü kişiler tarafindan bilinemez.

- Gerçekte fiziki olarak mevcut olmadığı için fiziksel olarak taşınması mümkün değildir.

- İşyerleri için herhangi bir komisyon uygulanmamaktadır.

- Transfer ücretleri diğer enstrümanlara göre çok düşüktür.

- Sinırlı sayıda olduğundan dolayı herhangi bir enflasyona neden olmamaktadır.

- Merkezi bir yapı tarafından kontrol edilemediğinden üzerinde çeşitli işlemler yapılmasını engellemektedir.

Kripto paraların avantajları yanında çeşitli dezavantajları da mevcuttur. Bu dezavantajlar ise şu şekilde sıralanabilir (Tüfek, 2017, s. 79):

- Yasal olarak hiçbir kurum arkasında bulunmamaktadır.

- Gerçek dünyada olmadığı için, az sayıda kişi tarafından kullanılmaktadır ve resmi olarak çeşitli ödemelerde kullanılamamaktadır.

- Kripto paralar, sanal paralar oldukları için yapılan işlemlerin geri alınması mümkün değildir. 
- Kripto paralar tamamen spekülatif olduğundan dolayı değerleri aniden düşebilir ve aniden yükselebilir.

- Enflasyona neden olmamasına rağmen deflasyona neden olabilir. Çünkü söz konusu kripto paranın arzı bittikten sonra söz konusu kripto paranın değeri aşırı yükselebilir.

- Kripto paralara yatırım yapmayı planlayan yatırımcılar bu avantaj ve dezavantajları göz önünde bulundurmalıdır.

\subsection{Kripto Para Borsaları}

Kripto para borsaları, bir kripto paranın diğer bir kripto para ile değiştirilebileceği çevrim içi platformlar olarak tanımlanabilir. Dünya genelinde en fazla işlem hacmine sahip kripto para borsaları Binance, Bithumb, BitMEX, Bitfinex, OKEx olarak sayılabilir. Ülkemizde ise en fazla faaliyet gösteren kripto para borsaları Koineks, BTCTurk, VeBitcoin, Paribu, Koinim, Borsabit, Digilira, Bitturk, Ovis şeklindedir (Akcan, 2018, s. 21-24).

Dünyada faaliyet gösteren 200'ün üzerinde kripto para borsası bulunmakla birlikte genel olarak dört farklı kripto para borsasından bahsetmek mümkündür (Akcan, 2018, s. 22; (https://cryptocurrencyfacts.com/what-is-a-cryptocurrency-exchange):

Geleneksel Kripto Para Borsalart: Alıc1lar ile satıcıların, kripto para birimlerini mevcut piyasa fiyatlarına göre alım ve satım yaptıkları geleneksel borsaya benzeyen borsa türüdür. $\mathrm{Bu}$ tarz borsalar genel olarak yapılan işlemler için belli miktarda ücret talep etmektedir.

Kripto Para Brokerları: Müşterilerin kripto paraları, piyasa fiyatının biraz üzerinden brokerlar aracılığıyla alım ve satım yapmasına izin veren web tabanlı borsalardır. Kullanım kolaylığı nedeniyle kripto para alım ve satımına yeni başlayanlar için uygun bir yöntemdir.

Doğrudan Ticaret Platformları: Bu tür platformlar, alıcılar ile satıcıların doğrudan ticaret imkânı sunması yanında sabit bir piyasa fiyatı üzerinde işlem yapmamaktadır. Bunun yerine satıcılar, işlem yapacak olduğu kripto paranın fiyatlarını kendisi belirleyerek alıcılara ulaşmaktadır.

Kripto Para Fonlart: Fonlar, kamu kesimi tarafindan fon üzerinden kripto para satın almalarını ve aldıkları kripto paraları tutmalarını sağlayan, profesyonel bir şekilde kripto paraların yönetildiği varlıkların havuzudur. Bu tarz borsalar, doğrudan satın almak veya saklamak zorunda olmadan kripto para birimine yatırım imkânı tanımaktadır.

\section{Bulanık Mantık}

Gerçek dünyada olaylar karmaşık bir durumdadır ve bu karmaşık olayların matematiksel ifadelerle gösterilmesi mümkün olmadığından yaklaşık olarak ifade edilebilirler. Belirsizlik durumunu gösteren bu yaklaşık ifadeler bulanıklığı ifade etmektedir. Bu belirsizliklerin sözel ifadeler kullanılarak daha belirgin hale gelmesi için geliştirilen mantığa "Bulanık Mantık" denilmektedir (Uygunoğlu ve Ünal, 2005, s. 14).

Bulanık mantık ilk defa Lotfi Zadeh (1965) tarafından, doğal dildeki belirsizliği modellemek için ortaya konmuştur. Bulanık mantık, klasik iki değerli mantığın genelleştirilmiş halidir ve bulanık kümeleri kullanan bütün teorileri ifade eder. Bulanık mantığın temelini oluşturan görüş, bir önermenin doğruluğunun, önermelerle, kesin yanlış ve kesin doğru arasındaki sonsuz sayıda doğruluk değerlerini içeren bir kümedeki değerler ya da sayısal olarak 0 ve 1 gerçel sayı aralığıyla ilişkilendiren fonksiyon olarak kabulüdür (Baykal ve Beyan, 2004, s. 39).

\subsection{Bulanık Küme Teorisi}

Bulanık küme, devamlı üyelik derecesine sahip nesnelerin oluşturduğu kümedir ve her nesneyi 0 ile 1 arasında değişen üyelik derecesine sahip üyelik fonksiyonu ile nitelendirir (Zadeh, 1965, s. 338). Üyelik fonksiyonu, küme üyelerinin değerleri ile değişiklik gösteren eğriye verilen addır. $E$ evrensel kümesinde tanımlı, bulanık küme $A$ için $\mu_{A}$ üyelik fonksiyonu $\mu_{A}: E \rightarrow[0,1]$ 
şeklinde ifade edilir. Yine bulanık $A$ kümesindeki $x$ elemanı için üyelik derecesinin gösterimi $A=\left\{\left(x, \mu_{A}(x)\right) \mid x \in E\right\}$ şeklindedir (Zimmermann, 2001, s. 12). $\mu_{A}$ üyelik fonksiyonu, [0,1] kapalı aralığında gerçek bir sayıyı ifade etmektedir (Zadeh, 1975, s. 222). "0" nesnenin kümenin üyesi olmadığını, "1" ise nesnenin kümenin tam üyesi olduğunu ve bu iki sayı arasındaki herhangi bir değer ise nesnenin kümeye üyelik derecesini veya kısmi üyeliğini ifade etmektedir (Kaufmann ve Gupta, 1988, s. 13).

\subsection{Bulanık Sayılar}

Bulanık sayı $\not c k$ konveks normalize bulanık kümedir:

$\left.-\quad x_{0} \in R, \mu_{q d} x_{0}\right)=1 \quad\left(x_{0}, \not c^{\prime}\right.$ 'nın orta değeridir $)$

- $\quad \mu_{\AA} x$ ) devamlıdir (Zimmermann, 2001, s. 59).

Uygulamanın alanına göre farklı bulanık sayılar kullanılabilmektedir. Genelde uygulamalarda sıklıkla kullanılan üçgen ve yamuk bulanık sayılardır (Baykal ve Beyan, 2004, s. 234). Bu çalışmada, bulanık CODAS yönteminde üçgen bulanık sayılar ile uygulama yapılmıştır.

Üçgen bulanık sayı, üç adet gerçek sayıyla tanımlanmış bulanık sayıların özel bir türüdür ve $\left(a_{1}, a_{2}, a_{3}\right)$ şeklinde ifade edilir. $a_{1}, a_{2}$ ve $a_{3}$ parametreleri sırasıyla en küçük olası değeri, en olası değeri ve en büyük olası değeri göstermektedir. Üçgen bulanık \&̌c sayısı Şekil 1'de görülmektedir (Karakaşoğlu, 2008, s. 86).

Şekil 1. Üçgen bulanık sayı

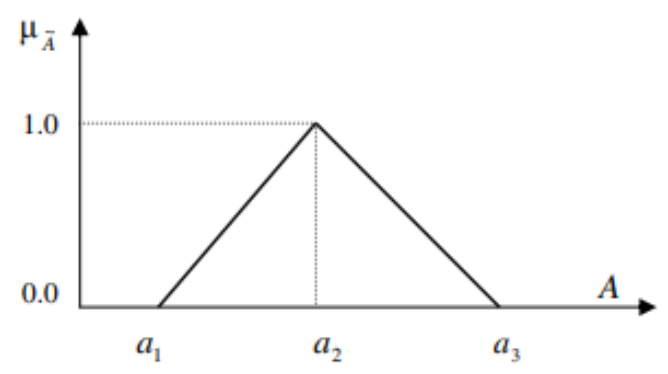

Üçgen bulanık sayının üyelik fonksiyonu Eşitlik (1)'de verildiği gibidir:

$$
\mu\left(x / A^{\circ}\right)= \begin{cases}0, & x<a_{1}, \\ \left(x-a_{1}\right) /\left(a_{2}-a_{1}\right), & a_{1} \leq x \leq a_{2}, \\ \left(a_{3}-x\right) /\left(a_{3}-a_{2}\right), & a_{2} \leq x \leq a_{3}, \\ 0, & x>a_{3}\end{cases}
$$

$\left(a_{1}, a_{2}, a_{3}\right)$ ve $\left(b_{1}, b_{2}, b_{3}\right)$ pozitif iki üçgen bulanık sayı ve $k$ sabit sayı olmak üzere, üçgen bulanık sayılarda işlemler Eşitlik (2) - (7) arasında görüldüğü gibidir:

$$
\begin{aligned}
& \left(a_{1}, a_{2}, a_{3}\right) \oplus\left(b_{1}, b_{2}, b_{3}\right)=\left(a_{1}+b_{1}, a_{2}+b_{2}, a_{3}+b_{3}\right) \\
& \left(a_{1}, a_{2}, a_{3}\right) \ominus\left(b_{1}, b_{2}, b_{3}\right)=\left(a_{1}-b_{3}, a_{2}-b_{2}, a_{3}-b_{1}\right) \\
& \left(a_{1}, a_{2}, a_{3}\right) \otimes\left(b_{1}, b_{2}, b_{3}\right)=\left(a_{1} . b_{1}, a_{2} . b_{2}, a_{3} . b_{3}\right) \\
& \left(a_{1}, a_{2}, a_{3}\right) \otimes \mathrm{k}=\left(a_{1} \cdot k, a_{2} \cdot k, a_{3} \cdot k\right) \text { ĕger } k \geq 0 \text { ise } \\
& \left(a_{1}, a_{2}, a_{3}\right) \otimes \mathrm{k}=\left(a_{3} . k, a_{2} . k, a_{1} \cdot k\right) \text { ĕger } k<0 \text { ise } \\
& \left(a_{1}, a_{2}, a_{3}\right) \oslash\left(b_{1}, b_{2}, b_{3}\right)=\left(a_{1} / b_{3}, a_{2} / b_{2}, a_{3} / b_{1}\right) \\
& \left(a_{1}, a_{2}, a_{3}\right) \oslash \mathrm{k}=\left(a_{1} / k, a_{2} / k, a_{3} / k\right) \text { eğer } k>0 \text { ise } \\
& \left(a_{1}, a_{2}, a_{3}\right) \oslash \mathrm{k}=\left(a_{3} / k, a_{2} / k, a_{1} / k\right) \text { eğer } k<0 \text { ise }
\end{aligned}
$$




\section{Bulanık CODAS Yöntemi}

CODAS (COmbinative Distance-based ASsessment) yöntemi, Keshavarz Ghorabaee vd. (2016) tarafından geliştirilen ÇKKV yöntemlerinden bir tanesidir. CODAS yönteminde alternatiflerin tercih edilmesi iki ölçü kullanılarak belirlenmektedir. Bu ölçüler Öklid ve Taxicap uzaklıklarıdır. Öklid uzaklığı, alternatiflerin negatif ideale olan uzaklığı ile ilgilidir. Taxicap uzaklığı ise normal kayıtsızlık alanı ile ilgilidir (Keshavarz Ghorabaee vd., 2016, s. 28). Ancak Öklid ve Taxicap uzaklıkları kesin ortamda tanımlandığından dolayı bu uzaklıkları bulanık durumlarda kullanmak mümkün değildir. $\mathrm{Bu}$ nedenle bulanık CODAS yönteminde, kesin uzaklıklar yerine bulanık ağırlıklı Hamming uzaklığı ve bulanık ağırlıklı Öklid uzaklığı kullanılmaktadır (Keshavarz Ghorabaee vd., 2017, s. 7).

Bulanık CODAS yönteminin çeşitli alanlarda uygulamaları mevcuttur. Bu çalışmalara, pazar segmentinin değerlendirilmesi (Keshavarz Ghorabaee vd., 2017), gübre endüstrisinde en iyi bakım stratejisinin seçilmesi (Panchal vd., 2017), üretim firması için tedarikçi seçimi (Boltürk, 2018), doğal gaz teknoloji firması seçimi (Boltürk ve Kahraman, 2018), personel seçim problemi (Yeni ve Özçelik, 2018, Yalçın ve Yapıcı Pehlivan; 2019), bulut bilişim sistemleri seçimi (Dahooie vd., 2019) örnek olarak verilebilir.

Bulanık CODAS yönteminin çözüm adımları aşağıdaki gibidir (Keshavarz Ghorabaee vd., 2017, s. 7-9):

1.Adım: Öncelikle karar vericiler tarafindan kriterler ve alternatifler belirlenir. $\mathrm{Bu}$ belirlenen kriterler ve alternatifler Tablo 1 ve Tablo 2'de yer alan sözel değişkenlerden yararlanarak karar vericiler tarafından değerlendirilir. Daha sonra, karar vericiler tarafından değerlendirilen karar matrislerinin ortalamaları alınarak ortalama bulanık karar matrisi Eşitlik 8 'de görüldüğ ü gibi elde edilir.

Tablo 1. Alternatifler için sözel değişkenler

\begin{tabular}{ll}
\hline Sözel Değişkenler & Bulanık Sayılar \\
\hline Çok Düşük (ÇD) & $(0,0,1)$ \\
Düşük (D) & $(0,1,3)$ \\
Orta Düşük (OD) & $(1,3,5)$ \\
Orta (O) & $(3,5,7)$ \\
Orta Yüksek (OY) & $(5,7,9)$ \\
Yüksek (Y) & $(7,9,10)$ \\
Çok Yüksek (ÇY) & $(9,10,10)$ \\
\hline
\end{tabular}

Kaynak: Chen, 2000, s. 5

Tablo 2. Kriterler için sözel değişkenler

\begin{tabular}{ll}
\hline Sözel Değişkenler & Bulanık Sayılar \\
\hline Çok Düşük (ÇD) & $(0.0,0.0,0.1)$ \\
Düşük (D) & $(0.0,0.1,0.3)$ \\
Orta Düşük (OD) & $(0.1,0.3,0.5)$ \\
Orta (O) & $(0.3,0.5,0.7)$ \\
Orta Yüksek (OY) & $(0.5,0.7,0.9)$ \\
Yüksek (Y) & $(0.7,0.9,1.0)$ \\
Çok Yüksek (ÇY) & $(0.9,1.0,1.0)$ \\
\hline
\end{tabular}

Kaynak: Chen, 2000, s. 5 


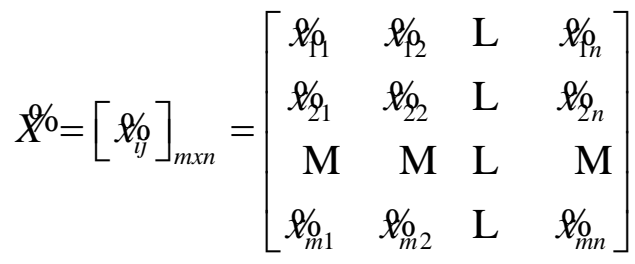

Bu matriste $\ell_{y j}, i$. alternatifin $(i=1,2, \ldots, m), j$. kriter $(j=1,2, \ldots, n)$ için ortalama bulanık performans değerini göstermektedir.

2. Adım: Karar vericiler tarafından oluşturulan ortalama bulanık karar matrisi, fayda kriterleri için Eşitlik 10 ve maliyet kriterleri için Eşitlik 11 kullanılarak normalize karar matrisine dönüştürülür.

$\widetilde{\mathrm{N}}=\left[\tilde{\mathrm{n}}_{\mathrm{ij}}\right]_{\mathrm{mxn}} ;$

$$
\tilde{\mathrm{n}}_{\mathrm{ij}}=\left\{\begin{array}{lr}
\frac{\tilde{\mathrm{x}}_{\mathrm{ij}}}{\max \varphi\left(\tilde{\mathrm{x}}_{\mathrm{ij}}\right)} & \text { fayda kriteri için } \\
1-\left(\frac{\tilde{\mathrm{x}}_{\mathrm{ij}}}{\max \varphi\left(\tilde{\mathrm{x}}_{\mathrm{ij}}\right)}\right) & \text { maliyet kriteri için }
\end{array}\right.
$$
edilir.

3. Adım: Eşitlik 12 ve Eşitlik 13 yardımıyla ağırıklı normalize bulanık karar matrisi elde

$$
\begin{aligned}
& \widetilde{\mathrm{R}}=\left[\tilde{\mathrm{r}}_{\mathrm{ij}}\right]_{\mathrm{mxn}} \\
& \tilde{\mathrm{r}}_{\mathrm{ij}}=\left(\widetilde{\mathrm{w}}_{\mathrm{j}} \otimes \tilde{\mathrm{n}}_{\mathrm{ij}}\right)
\end{aligned}
$$

Eşitlik 13’te, $\widetilde{\mathrm{w}}_{\mathrm{j}}, j$. kriterin bulanık ağırlığını göstermektedir. edilir.

4. Adım: Eşitlik 14 ve Eşitlik 15 yardımıyla bulanık negatif ideal çözüm değerleri elde

$$
\begin{aligned}
\widetilde{\mathrm{NS}} & =\left[\widetilde{\mathrm{ns}}_{\mathrm{j}}\right]_{1 \times n} \\
\widetilde{\mathrm{ns}}_{\mathrm{j}} & =\min _{\mathrm{i}} \tilde{\mathrm{r}}_{\mathrm{ij}}
\end{aligned}
$$

5. Adım: Her bir alternatifin bulanık negatif ideal çözüme olan ağırlıklı Öklid uzaklık değerleri (ED) Eşitlik 16 ve Eşitlik 17, ağırlıklı Hamming uzaklık değerleri (HD) Eşitlik 18 ve Eşitlik 19 yardımıyla hesaplanır. İki üçgen bulanık sayı $\widetilde{A}=\left(a_{1}, a_{2}, a_{3}\right)$ ve $\widetilde{B}=\left(b_{1}, b_{2}, b_{3}\right)$ olmak üzere;

$$
\begin{aligned}
& \mathrm{ED}_{\mathrm{i}}=\sum_{\mathrm{j}=1}^{\mathrm{n}} \mathrm{d}_{\mathrm{E}}\left(\tilde{\mathrm{r}}_{\mathrm{ij}}, \widetilde{\mathrm{ns}}_{\mathrm{j}}\right) \\
& \mathrm{d}_{\mathrm{E}}(\widetilde{\mathrm{A}}, \widetilde{\mathrm{B}})=\sqrt{\frac{\left(\mathrm{a}_{1}-\mathrm{b}_{1}\right)^{2}+2\left(\mathrm{a}_{2}-\mathrm{b}_{2}\right)^{2}+\left(\mathrm{a}_{3}-\mathrm{b}_{3}\right)}{4}} \\
& \mathrm{HD}_{\mathrm{i}}=\sum_{\mathrm{j}=1}^{\mathrm{n}} \mathrm{d}_{\mathrm{H}}\left(\widetilde{\mathrm{r}}_{\mathrm{ij}}, \widetilde{\mathrm{ns}}_{\mathrm{j}}\right) \\
& \mathrm{d}_{\mathrm{H}}(\widetilde{\mathrm{A}}, \widetilde{\mathrm{B}})=\frac{\left|\mathrm{a}_{1}-\mathrm{b}_{1}\right|+2\left|\mathrm{a}_{2}-\mathrm{b}_{2}\right|+\left|\mathrm{a}_{3}-\mathrm{b}_{3}\right|}{4}
\end{aligned}
$$

6. Adım: Eşitlik 20 ve Eşitlik 21 yardımıyla göreli değerlendirme matrisi elde edilir.

$\mathrm{RA}=\left[\mathrm{p}_{i k}\right]_{m \times m}$

$\mathrm{p}_{\mathrm{ik}}=\left(\mathrm{ED}_{\mathrm{i}}-\mathrm{ED}_{\mathrm{k}}\right)+\mathrm{t}(\mathrm{x}) \cdot\left(\mathrm{HD}_{\mathrm{i}}-\mathrm{HD}_{\mathrm{k}}\right)$

$\mathrm{t}(\mathrm{x})$ eşik fonksiyonu ve $k=(1,2, \ldots, m)$ olmak üzere; 
$t(x)=\left\{\begin{array}{l}1, \text { eğer }\left|E D_{i}-E D_{k}\right| \geq \theta \\ 0, \text { eğer }\left|E D_{i}-E D_{k}\right|<\theta\end{array}\right.$

Eşitlik 22 'de $\theta$ eşik değeridir ve bu değer karar verici tarafından belirlenir. Bu çalışmada, hesaplamalarda $\theta=0,02$ olarak alınmıştır.

7. Adım: Eşitlik 23 yardımıyla her alternatifin değerlendirme skorları hesaplanır.

$\mathrm{AS}_{\mathrm{i}}=\sum_{\mathrm{k}=1}^{\mathrm{n}} \mathrm{p}_{\mathrm{ik}}$

8. Adım: Değerlendirme skorları en yüksek olandan en düşük olana doğru sıralanır. En yüksek değerlendirme skoruna sahip olan alternatif tercih edilir.

\section{Uygulama}

Bireyler, gelecekte karşılaşabilecekleri olumlu ve olumsuz çeşitli durumlara karşı önceden tedbir almaktadır. Bu tedbirler altın, döviz, bono gibi değerli kağıtlara yapılan yatırımlar olabileceği gibi, çeşitli taşınır veya taşınmaz mallara yapılan yatırımlar da olabilir. Özellikle, internetin son yıllarda hızla gelişmesi ile ortaya çıkan ve sayıları her geçen gün artarak yatırım tercihleri arasına giren kripto paralar da yatırım alternatifi olarak değerlendirilmektedir. $\mathrm{Bu}$ çalışmada, çeşitli yatırım alternatiflerine yatırım yapan yatırımcıların, internetin gelişmesi ile ortaya çıan ve her geçen gün kullanımı giderek artan kripto paralara yatırım yapabilmesi için en uygun alternatifin seçim problemi ele alınmıştır.

Kripto paralar hakkında geniş bilgi birikimine sahip ve daha önce yatırım alternatifi olarak kripto paraları tercih etmiş olan 3 karar vericinin değerlendirmede bulunduğu bu çalışmada, en çok işlem gören 10 kripto para alternatifi, karar vericiler tarafından belirlenen 10 kriter altında, yeni bir ÇKKV yöntemi olan bulanık CODAS yöntemi yardımıyla değerlendirilmiştir.

En uygun kripto para yatırım alternatifi seçiminde dikkate alınan alternatif kripto paralar (https://tr.investing.com) Tablo 3'te gösterilmiştir.

Tablo 3. Alternatifler

\begin{tabular}{cc}
\hline Alternatif Kodu & Alternatif \\
\hline BTC & Bitcoin \\
ETH & Ethereum \\
XRP & Ripple \\
LTC & Litecoin \\
EOS & EOS \\
BCH & Bitcoin Cash \\
BNB & Binance Coin \\
USDT & Tether \\
XLM & Stellar Lumens \\
TRX & TRON \\
\hline
\end{tabular}

En uygun kripto para yatırım alternatifi seçiminde dikkate alınan 10 kriter, karar vericiler ile gerçekleştirilen görüşmeler sonrasında belirlenmiş ve Tablo 4'te gösterilmiştir. 
Tablo 4. Kriterler

\begin{tabular}{ll}
\hline Kriter Kodu & Kriter \\
\hline $\mathrm{K}_{1}$ & Coin Ekibi /Geliştiriciler \\
$\mathrm{K}_{2}$ & Y1llık Ortalama Getiri \\
$\mathrm{K}_{3}$ & Toplam Piyasa Değeri \\
$\mathrm{K}_{4}$ & Roadmap \\
$\mathrm{K}_{5}$ & White Paper \\
$\mathrm{K}_{6}$ & Güvenlik \\
$\mathrm{K}_{7}$ & İşlem Hızı \\
$\mathrm{K}_{8}$ & Destekleyen Kurum ve Kuruluşlar \\
$\mathrm{K}_{9}$ & En Yüksek Değerden Değişim \\
$\mathrm{K}_{10}$ & İşlem Gördüğü Borsa Sayısı \\
\hline
\end{tabular}

Coin Ekibi / Geliştiriciler $\left(\mathbf{K}_{1}\right)$ : Kripto parayı ortaya çıkaran ve geliştiren kişi/kişiler ya da kurum/kuruluşların alanında uzman olup olmadığını gösteren kriterdir.

Yıllık Ortalama Getiri $\left(\mathbf{K}_{2}\right)$ : Kripto paraya yatırım yapıldığında y1llık getireceği geliri gösteren kriterdir.

Toplam Piyasa Değeri $\left(\mathbf{K}_{3}\right)$ : Pazar payını, piyasa olgunluğunu ve piyasadaki kabulünü ölçmek için kullanılacak olan kriterdir (Genç vd. 2018, s. 5).

Roadmap $\left(\mathbf{K}_{4}\right)$ : Kripto paraların coin ekibi/geliştiricileri tarafından gelecekte çıarmayı planladıkları ürünleri ve çalışmaları tarih belirterek başta yatırımcılar olmak üzere herkes tarafından erişilebilmesini, böylelikle de coin ekibi/geliştiricilerin vaatlerini yerine getirip getirmediklerini ifade eden kriterdir.

White Paper $\left(\mathbf{K}_{5}\right)$ : Kripto paraların teknolojik detaylarını, hedeflerini ve getireceği yenilikleri anlatan ve bu bilgilerle kullanıcıya karar aldırma niteliği bulunduran yazı hakkında fikir veren kriterdir (https://kriptokoin.com/white-paper).

Güvenlik $\left(\mathbf{K}_{\mathbf{6}}\right)$ : Kripto paraların, sanal para olmalarından dolayı internet üzerinden gelebilecek siber saldırılara karşı dayanıklı olmalarını ifade eden kriterdir.

İşlem $\mathbf{H ı z ı}\left(\mathbf{K}_{7}\right)$ : 7 gün 24 saat işlem alım-satımı yapılabilen kripto paraların saniyede yapılan işlem hızının yüksek olmasını ve ağ güvenliğinin sağlanabilmesi amacıyla geçmesi gereken onayların hızlı bir şekilde gerçekleşmesi gerektiğini ifade eden kriterdir.

Destekleyen Kurum ve Kuruluşlar $\left(\mathbf{K}_{\mathbf{8}}\right)$ : Kripto para geliştiricilerini destekleyen kurum ve kuruluşların güvenilir olması yatırımcılar açısından yatırım yapılabilirliğini arttırmasını ifade eden kriterdir.

En Yüksek Değerden Değişim $\left(\mathbf{K}_{\mathbf{9}}\right)$ : Kar realizasyon miktarının değerlendirilmesi ve uzun vadede değerin ulaşabileceği nokta konusunda fikir veren kriterdir (Genç vd. 2018, s. 5).

İşlem Gördüğ̈̈̈ Borsa Sayısı $\left(\mathbf{K}_{10}\right)$ : Potansiyel olarak büyüyen bir coin olarak değerlendirilmesini sağlayan kriterdir (Genç vd. 2018, s. 5).

Karar vericiler tarafindan alternatiflerin ve kriterlerin belirlenmesinin ardından bulanık CODAS yöntemi ile en uygun kripto para alternatifi aşağıdaki adımlar yardımıyla seçilmiştir:

1. Adım: Alternatifler, Tablo 1'de yer alan sözel değişkenler yarımıyla 3 karar verici tarafından değerlendirilmiş ve bu değerlendirmeler Tablo 5'te gösterilmiştir. Daha sonra, sözel değişkenlerin üçgen bulanık sayı karşılıklarının ortalaması alınarak ortalama bulanık karar matrisi oluşturulmuş ve Tablo 6' da verilmiştir. 
Tablo 5. Karar vericiler tarafindan olușturulan bulanık karar matrisleri

\begin{tabular}{|c|c|c|c|c|c|c|c|c|c|c|c|}
\hline & Alternatifler & $\mathbf{K}_{1}$ & $\mathbf{K}_{2}$ & $\mathbf{K}_{\mathbf{3}}$ & $\mathbf{K}_{4}$ & $\mathbf{K}_{5}$ & $\mathbf{K}_{6}$ & $\mathbf{K}_{7}$ & $\mathbf{K}_{8}$ & $\mathbf{K}_{9}$ & $K_{10}$ \\
\hline \multirow{10}{*}{$\vec{z}$} & BTC & ÇY & Y & ÇY & ÇY & ÇY & ÇY & $\mathrm{Y}$ & ÇY & ÇY & ÇY \\
\hline & ETH & ÇY & Y & ÇY & ÇY & ÇY & ÇY & $\mathrm{Y}$ & ÇY & ÇY & ÇY \\
\hline & XRP & ÇY & OY & ÇY & ÇY & ÇY & ÇY & ÇY & ÇY & ÇY & ÇY \\
\hline & LTC & ÇY & Y & ÇY & ÇY & ÇY & ÇY & ÇY & Y & ÇY & ÇY \\
\hline & EOS & ÇY & Y & ÇY & $\mathrm{Y}$ & Y & $\mathrm{Y}$ & ÇY & $\mathrm{Y}$ & ÇY & ÇY \\
\hline & ВCH & ÇY & OY & ÇY & $\mathrm{Y}$ & Y & ÇY & ÇY & Y & ÇY & ÇY \\
\hline & BNB & ÇY & ÇY & ÇY & ÇY & ÇY & ÇY & Y & ÇY & ÇY & $\mathrm{O}$ \\
\hline & USDT & ÇY & ÇD & ÇY & OY & OY & OY & OY & ÇY & OS & ÇY \\
\hline & XLM & ÇY & Y & ÇY & ÇY & ÇY & ÇY & ÇY & ÇY & ÇY & ÇY \\
\hline & TRX & Y & ÇY & $\mathrm{Y}$ & Y & OY & Y & Y & Y & $\mathrm{Y}$ & $\mathrm{Y}$ \\
\hline \multirow{10}{*}{$z^{2}$} & BTC & ÇY & Y & ÇY & ÇY & ÇY & ÇY & $\mathrm{Y}$ & ÇY & ÇY & ÇY \\
\hline & ETH & ÇY & $\mathrm{Y}$ & OY & ÇY & $\mathrm{Y}$ & ÇY & $\mathrm{Y}$ & ÇY & ÇY & ÇY \\
\hline & XRP & ÇY & $Y$ & OY & ÇY & Y & ÇY & ÇY & ÇY & ÇY & ÇY \\
\hline & LTC & $\mathrm{Y}$ & $\mathrm{Y}$ & OD & $\mathrm{Y}$ & $\mathrm{Y}$ & $\mathrm{Y}$ & ÇY & $\mathrm{Y}$ & $\mathrm{Y}$ & ÇY \\
\hline & EOS & ÇY & Y & OD & Y & Y & ÇY & ÇY & ÇY & Y & $\mathrm{Y}$ \\
\hline & BCH & Y & OY & OD & OY & $\mathrm{Y}$ & Y & Y & OY & ÇY & $\mathrm{Y}$ \\
\hline & BNB & Y & ÇY & OD & Y & $\mathrm{Y}$ & $\mathrm{Y}$ & Y & Y & ÇY & OD \\
\hline & USDT & $\mathrm{Y}$ & ÇD & OD & OY & OY & OY & $\mathrm{Y}$ & $\mathrm{Y}$ & OD & ÇY \\
\hline & XLM & $\mathrm{Y}$ & Y & $\mathrm{O}$ & Y & Y & ÇY & ÇY & $\mathrm{Y}$ & Y & Y \\
\hline & TRX & Y & ÇY & OD & OY & $\mathrm{O}$ & OY & OY & OY & Y & $\mathrm{OY}$ \\
\hline \multirow{10}{*}{$\mathbb{Z}^{m}$} & BTC & $\mathrm{Y}$ & $\mathrm{Y}$ & ÇY & ÇY & $\mathrm{Y}$ & ÇY & $\mathrm{Y}$ & ÇY & ÇY & ÇY \\
\hline & ETH & Y & $Y$ & $Y$ & ÇY & $\mathrm{Y}$ & ÇY & $\mathrm{Y}$ & ÇY & ÇY & ÇY \\
\hline & XRP & Y & Y & Y & ÇY & $\mathrm{Y}$ & ÇY & ÇY & ÇY & ÇY & ÇY \\
\hline & LTC & OY & Y & OY & Y & Y & Y & ÇY & Y & Y & ÇY \\
\hline & EOS & OY & $\mathrm{Y}$ & OY & OY & $\mathrm{Y}$ & $\mathrm{Y}$ & ÇY & $\mathrm{Y}$ & $\mathrm{Y}$ & OY \\
\hline & ВCH & OY & $\mathrm{Y}$ & OY & OY & $\mathrm{Y}$ & $\mathrm{Y}$ & Y & OY & Y & OY \\
\hline & BNB & OY & ÇY & OD & $\mathrm{Y}$ & $\mathrm{Y}$ & OY & $\mathrm{Y}$ & $\mathrm{Y}$ & $Y$ & $\mathrm{Y}$ \\
\hline & USDT & OY & D & OY & OY & OY & OY & OY & OY & OD & ÇY \\
\hline & XLM & OY & OY & OY & Y & Y & Y & Y & Y & Y & Y \\
\hline & TRX & $\mathrm{OY}$ & $\mathrm{Y}$ & OD & $\mathrm{OY}$ & $\mathrm{O}$ & $\mathrm{OY}$ & $\mathrm{OY}$ & OY & $\mathrm{OY}$ & $\mathrm{O}$ \\
\hline
\end{tabular}

Tablo 6. Ortalama bulanık karar matrisi

\begin{tabular}{cccccc}
\hline & BTC & ETH & XRP & LTC & EOS \\
\hline $\mathbf{K}_{\mathbf{1}}$ & $(8.33,9.67,10)$ & $(8.33,9.67,10)$ & $(8.33,9.67,10)$ & $(7,8.67,9.67)$ & $(7.67,9,9.67)$ \\
$\mathbf{K}_{\mathbf{2}}$ & $(7,9,10)$ & $(7,9,10)$ & $(6.33,8.33,9.67)$ & $(7,9,10)$ & $(7,9,10)$ \\
$\mathbf{K}_{\mathbf{3}}$ & $(9,10,10)$ & $(7,8.67,9.67)$ & $(7,8.67,9.67)$ & $(5,6.67,8)$ & $(5,6.67,8)$ \\
$\mathbf{K}_{\mathbf{4}}$ & $(9,10,10)$ & $(9,10,10)$ & $(9,10,10)$ & $(7.67,9.33,10)$ & $(6.33,8.33,9.67)$ \\
$\mathbf{K}_{\mathbf{5}}$ & $(8.33,9.67,10)$ & $(7.67,9.33,10)$ & $(7.67,9.33,10)$ & $(7.67,9.33,10)$ & $(7,9,10)$ \\
$\mathbf{K}_{\mathbf{6}}$ & $(9,10,10)$ & $(9,10,10)$ & $(9,10,10)$ & $(7.67,9.33,10)$ & $(7.67,9.33,10)$ \\
$\mathbf{K}_{\mathbf{7}}$ & $(7,9,10)$ & $(7,9,10)$ & $(9,10,10)$ & $(9,10,10)$ & $(9,10,10)$ \\
$\mathbf{K}_{\mathbf{8}}$ & $(9,10,10)$ & $(9,10,10)$ & $(9,10,10)$ & $(7,9,10)$ & $(7.67,9.33,10)$ \\
$\mathbf{K}_{\mathbf{9}}$ & $(9,10,10)$ & $(9,10,10)$ & $(9,10,10)$ & $(7.67,9.33,10)$ & $(7.67,9.33,10)$ \\
$\mathbf{K}_{\mathbf{1 0}}$ & $(9,10,10)$ & $(9,10,10)$ & $(9,10,10)$ & $(9,10,10)$ & $(7,8.67,9.67)$ \\
\hline
\end{tabular}


Tablo 6. (Devam) Ortalama bulanık karar matrisi

\begin{tabular}{cccccc}
\hline & $\mathbf{B C H}$ & $\mathbf{B N B}$ & USDT & XLM & TRX \\
\hline $\mathbf{K}_{\mathbf{1}}$ & $(7,8.67,9.67)$ & $(7,8.67,9.67)$ & $(7,8.67,9.67)$ & $(7,8.67,9.67)$ & $(6.33,8.33,9.67)$ \\
$\mathbf{K}_{\mathbf{2}}$ & $(5.67,7.67,9.33)$ & $(9,10,10$ & $(0,0,33,1.67)$ & $(6.33,8.33,9.67)$ & $(8.33,9.67,10)$ \\
$\mathbf{K}_{\mathbf{3}}$ & $(5,6.67,8)$ & $(3.67,5.33,6.67)$ & $(5,6.67,8)$ & $(5.67,7.33,8.67)$ & $(3,5,6.67$ \\
$\mathbf{K}_{\mathbf{4}}$ & $(5.67,7.67,9.33)$ & $(7.67,9.33,10)$ & $(5,7,9)$ & $(7.67,9.33,10)$ & $(5.677 .67,9.33)$ \\
$\mathbf{K}_{\mathbf{5}}$ & $(7,9,10)$ & $(7,9.33,10)$ & $(5,7,9)$ & $(7.67,9.33,10)$ & $(3.67,5.67,7.67)$ \\
$\mathbf{K}_{\mathbf{6}}$ & $(9.67,9.33,10)$ & $(7,8.67,9.67)$ & $(5,7,9)$ & $(8.33,9.67,10)$ & $(5.67,7.67,9.33)$ \\
$\mathbf{K}_{\mathbf{7}}$ & $(7.67,9.33,10)$ & $(7.67,9,10)$ & $(5.67,7.67,9.33)$ & $(8.33,9.67,10)$ & $(5.67,7.67,9.33)$ \\
$\mathbf{K}_{\mathbf{8}}$ & $(5.67,7.67,9.33)$ & $(7.67,9.33,10)$ & $(7,8.67,9.67)$ & $(7.67,9.33,10)$ & $(5.67,7.67,9.33)$ \\
$\mathbf{K}_{\mathbf{9}}$ & $(8.33,9.67,10)$ & $(8.33,9.67,10)$ & $(1.67,3.67,5.67)$ & $(7,9,10)$ & $(5.67,7.67,9.33)$ \\
$\mathbf{K}_{\mathbf{1 0}}$ & $(7,8.67,9.67)$ & $(2.33,4.33,6.33)$ & $(9,10,10)$ & $(7.67,9.33,10)$ & $(4.33,6.33,8.33)$ \\
\hline
\end{tabular}

2. Adım: Ortalama bulanık karar matrisinden yararlanarak tüm kriterler fayda kriteri olduğu için Eşitlik 10 ile normalize bulanık karar matrisi elde edilmiş ve Tablo 7'de gösterilmiştir.

Tablo 7. Normalize bulanık karar matrisi

\begin{tabular}{lccccc}
\hline & BTC & ETH & XRP & LTC & EOS \\
\hline $\mathbf{K}_{\mathbf{1}}$ & $(0.83,0.97,1)$ & $(0.33,0.97,1)$ & $(0.83,0.97,1)$ & $(0.7,0.87,0.97)$ & $(0.77,0.9,0.97)$ \\
$\mathbf{K}_{\mathbf{2}}$ & $(0.7,0.9,1)$ & $(0.7,0.9,1)$ & $(0.63,0.83,0.97$ & $(0.7,0.87,0.97)$ & $(0.7,0.9,1)$ \\
$\mathbf{K}_{\mathbf{3}}$ & $(0.9,1,1)$ & $(0.7,0.87,0.97)$ & $(0.7,0.87,0.97)$ & $(0.5,0.67,0.8)$ & $(0.5,0.67,0.8)$ \\
$\mathbf{K}_{\mathbf{4}}$ & $(0.9,1,1)$ & $(0.9,1,1)$ & $(0.9,1,1)$ & $(0.77,0.93,1)$ & $(0.63,0.83,0.97)$ \\
$\mathbf{K}_{\mathbf{5}}$ & $(0.83,0.97,1)$ & $(0.77,0.93,1)$ & $(0.77,0.93,1)$ & $(0.77,0.93,1)$ & $(0.7,0.9,1)$ \\
$\mathbf{K}_{\mathbf{6}}$ & $(0.9,1,1)$ & $(0.9,1,1)$ & $(0.9,1,1)$ & $(0.77,0.93,1)$ & $(0.77,0.93,1)$ \\
$\mathbf{K}_{\mathbf{7}}$ & $(0.7,0.9,1)$ & $(0.7,0.9,1)$ & $(0.9,1,1)$ & $(0.9,1,1)$ & $(0.9,1,1)$ \\
$\mathbf{K}_{\mathbf{8}}$ & $(0.9,1,1)$ & $(0.9,1,1)$ & $(0.9,1,1)$ & $(0.7,0.9,1)$ & $(0.77,0.93,1)$ \\
$\mathbf{K}_{\mathbf{9}}$ & $(0.9,1,1)$ & $(0.9,1,1)$ & $(0.9,1,1)$ & $(0.77,0.93,1)$ & $(0.77,0.93,1)$ \\
$\mathbf{K}_{\mathbf{1 0}}$ & $(0.9,1,1)$ & $(0.9,1,1)$ & $(0.9,1,1)$ & $(0.9,1,1)$ & $(0.7,0.87,0.97)$ \\
\hline
\end{tabular}

Tablo 7. (Devam) Normalize bulanık karar matrisi

\begin{tabular}{cccccc}
\hline & $\mathbf{B C H}$ & $\mathbf{B N B}$ & USDT & XLM & TRX \\
\hline $\mathbf{K}_{\mathbf{1}}$ & $(0.7,0.87,0.97)$ & $(0.7,0.87,0.97)$ & $(0.7,0.87,0.97)$ & $(0.7,0.87,0.97)$ & $(0.63,0.83,0.97)$ \\
$\mathbf{K}_{\mathbf{2}}$ & $(0.57,0.77,0.93)$ & $(0.9,1,1)$ & $(0,0.03,0.17)$ & $(0.63,0.83,0.97)$ & $(0.83,0.97,1)$ \\
$\mathbf{K}_{\mathbf{3}}$ & $(0.5,0.67,0.8)$ & $(0.37,0.53,0.67)$ & $(0.5,0.67,0.8)$ & $(0.57,0.73,0.87)$ & $(0.3,0.5,0.67)$ \\
$\mathbf{K}_{\mathbf{4}}$ & $(0.57,0.77,0.93)$ & $(0.77,0.93,1)$ & $(0.5,0.7,0.9)$ & $(0.77,0.93,1)$ & $(0.57,0.77,1)$ \\
$\mathbf{K}_{\mathbf{5}}$ & $(0.7,0.9,1)$ & $(0.77,0.93,1)$ & $(0.5,0.7,0.9)$ & $(0.77,0.93,1)$ & $(0.37,0.57,0.77)$ \\
$\mathbf{K}_{\mathbf{6}}$ & $(0.77,0.93,1)$ & $(0.7,0.87,0.97)$ & $(0.5,0.7,0.9)$ & $(0.83,0.97,1)$ & $(0.57,0.77,0.93)$ \\
$\mathbf{K}_{\mathbf{7}}$ & $(0.77,0.93,1)$ & $(0.7,0.9,1)$ & $(0.57,0.77,0.93)$ & $(0.83,0.97,1)$ & $(0.57,0.77,0.93)$ \\
$\mathbf{K}_{\mathbf{8}}$ & $(0.57,0.77,0.93)$ & $(0.77,0.93,1)$ & $(0.7,0.87,0.97)$ & $(0.77,0.93,1)$ & $(0.57,0.77,0.93)$ \\
$\mathbf{K}_{\mathbf{9}}$ & $(0.83,0.97,1)$ & $(0.83,0.97,1)$ & $(0.17,0.37,0.57)$ & $(0.7,0.9,1)$ & $(0.57,0.77,0.93)$ \\
$\mathbf{K}_{\mathbf{1 0}}$ & $(0.7,0.87,0.97)$ & $(0.23,0.43,0.63)$ & $(0.9,1,1)$ & $(0.77,0.93,1)$ & $(0.43,0.63,0.83)$ \\
\hline
\end{tabular}

3. Adım: Tablo 2'de yer alan sözel değişkenler ile kriterler 3 karar verici tarafından değerlendirilmiş ve bu değerlendirmelerin üçgen bulanık sayı karşılıklarının ortalamaları alınarak 
kriterlerin ağıllıkları bulunmuştur. Bulunan bu değerler Tablo 8'de gösterilmiştir. Daha sonra Eşitlik 12 ve Eşitlik 13 yardımıyla ağırlıklı normalize bulanık karar matrisi Tablo 9'da görüldüğü gibi elde edilmiştir.

Tablo 8. Kriterlerin ağırlık değerleri

\begin{tabular}{ccccc}
\hline & $\mathbf{K V}_{\mathbf{1}}$ & $\mathbf{K V}_{\mathbf{2}}$ & $\mathbf{K V}_{\mathbf{3}}$ & $\begin{array}{c}\text { Ortalama } \\
\text { Ăğlrlklar }\end{array}$ \\
\hline $\mathbf{K}_{\mathbf{1}}$ & $(0.7,0.9,1)$ & $(0.3,0.5,0.7)$ & $(0.5,0.7,0.9)$ & $(0.5,0.7,0.87)$ \\
$\mathbf{K}_{\mathbf{2}}$ & $(0.9,1,1)$ & $(0.9,1,1)$ & $(0.9,1,1)$ & $(0.9,1,1)$ \\
$\mathbf{K}_{\mathbf{3}}$ & $(0.7,0.9,1)$ & $(0.5,0.7,0.9)$ & $(0.5,0.7,0.9)$ & $(0.57,0.77,0.93)$ \\
$\mathbf{K}_{\mathbf{4}}$ & $(0.7,0.9,1)$ & $(0.7,0.9,1)$ & $(0.7,0.9,1)$ & $(0.7,0.9,1)$ \\
$\mathbf{K}_{\mathbf{5}}$ & $(0.9,1,1)$ & $(0.9,1,1)$ & $(0.9,1,1)$ & $(0.9,1,1)$ \\
$\mathbf{K}_{\mathbf{6}}$ & $(0.9,1,1)$ & $(0.7,0.9,1)$ & $(0.7,0.9,1)$ & $(0.77,0.93,1)$ \\
$\mathbf{K}_{\mathbf{7}}$ & $(0.5,0.7,0.9)$ & $(0.3,0.5,0.7)$ & $(0.5,0.7,0.9)$ & $(0.43,0.63,0.83)$ \\
$\mathbf{K}_{\mathbf{8}}$ & $(0.5,0.7,0.9)$ & $(0.3,0.5,0.7)$ & $(0.5,0.7,0.9)$ & $(0.43,0.63,0.83)$ \\
$\mathbf{K}_{\mathbf{9}}$ & $(0.5,0.7,0.9)$ & $(0.3,0.5,0.7)$ & $(0.7,0.9,1)$ & $(0.5,0.7,0.87)$ \\
$\mathbf{K}_{\mathbf{1 0}}$ & $(0.9,1,1)$ & $(0.7,0.9,1)$ & $(0.7,0.9,1)$ & $(0.77,0.93,1)$ \\
\hline
\end{tabular}

Tablo 9. Ağırlıklı normalize bulanık karar matrisi

\begin{tabular}{cccccc}
\hline & BTC & ETH & XRP & LTC & EOS \\
\hline $\mathbf{K}_{\mathbf{1}}$ & $(0.42,0.68,0.87)$ & $(0.42,0.68,0.87)$ & $(0.42,0.68,1)$ & $(0.35,0.61,0.84)$ & $(0.38,0.63,0.84)$ \\
$\mathbf{K}_{\mathbf{2}}$ & $(0.63,0.9,1)$ & $(0.63,0.9,1)$ & $(0.57,0.83,1)$ & $(0.63,0.9,1)$ & $(0.63,0.9,1)$ \\
$\mathbf{K}_{\mathbf{3}}$ & $(0.51,0.77,0.93)$ & $(0.40,0.67,0.9)$ & $(0.4,0.67,1)$ & $(0.29,0.51,0.74)$ & $(0.29,0.51,0.74)$ \\
$\mathbf{K}_{\mathbf{4}}$ & $(0.63,0.9,1)$ & $(0.63,0.9,1)$ & $(0.63,0.9,1)$ & $(0.54,0.84,1)$ & $(0.44,0.75,0.97)$ \\
$\mathbf{K}_{\mathbf{5}}$ & $(0.75,0.97,1)$ & $(0.69,0.93,1)$ & $(0.69,0.93,1)$ & $(0.69,0.93,1)$ & $(0.63,0.9,1)$ \\
$\mathbf{K}_{\mathbf{6}}$ & $(0.69,0.93,1)$ & $(0.69,0.93,1)$ & $(0.69,0.93,1)$ & $(0.59,0.87,1)$ & $(0.59,0.87,1)$ \\
$\mathbf{K}_{\mathbf{7}}$ & $(0.30,0.57,0.93)$ & $(0.30,0.57,0.83)$ & $(0.36,0.63,1)$ & $(0.39,0.63,0.83)$ & $(0.39,0.63,0.83)$ \\
$\mathbf{K}_{\mathbf{8}}$ & $(0.39,0.63,0.83)$ & $(0.39,0.63,0.83)$ & $(0.39,0.63,1)$ & $(0.3,0.57,0.83)$ & $(0.33,0.59,0.83)$ \\
$\mathbf{K}_{9}$ & $(0.45,0.7,0.87)$ & $(0.45,0.7,0.87)$ & $(0.45,0.7,1)$ & $(0.38,0.65,0.87)$ & $(0.38,0.65,0.87)$ \\
$\mathbf{K}_{\mathbf{1 0}}$ & $(0.69,0.93,1)$ & $(0.69,0.93,1)$ & $(0.69,0.93,1)$ & $(0.69,0.93,1)$ & $(0.54,0.81,0.97)$ \\
\hline
\end{tabular}

Tablo 9. (Devam) Ağırlıklı normalize bulanık karar matrisi

\begin{tabular}{cccccc}
\hline & BCH & BNB & USDT & XLM & TRX \\
\hline $\mathbf{K}_{\mathbf{1}}$ & $(0.35,0.61,0.84)$ & $(0.35,0.61,0.84)$ & $(0.35,0.6,0.84)$ & $(0.35,0.61,0.84)$ & $(0.32,0.58,0.84)$ \\
$\mathbf{K}_{\mathbf{2}}$ & $(0.51,0.77,0.93)$ & $(0.81,1,1)$ & $(0,0.03,0.17)$ & $(0.57,0.83,0.97)$ & $(0.75,0.97,1)$ \\
$\mathbf{K}_{\mathbf{3}}$ & $(0.29,0.51,0.74)$ & $(0.21,0.410 .62)$ & $(0.29,0.5,0.74)$ & $(0.32,0.56,0.81)$ & $(0.17,0.39,0.62)$ \\
$\mathbf{K}_{\mathbf{4}}$ & $(0.4,0.69,0.93)$ & $(0.54,0.84,1)$ & $(0.35,0.6,0.9)$ & $(0.54,0.84,1)$ & $(0.40,0.69,1)$ \\
$\mathbf{K}_{\mathbf{5}}$ & $(0.63,0.9,1)$ & $(0.69,0.93,1)$ & $(0.45,0.7,0.9)$ & $(0.69,0.93,1)$ & $(0.33,0.57,0.77)$ \\
$\mathbf{K}_{\mathbf{6}}$ & $(0.59,0.87,1)$ & $(0.54,0.81,0.97)$ & $(0.39,0.7,0.9)$ & $(0.64,0.9,1)$ & $(0.44,0.71,0.93)$ \\
$\mathbf{K}_{\mathbf{7}}$ & $(0.33,0.59,0.83)$ & $(0.3,0.57,0.83)$ & $(0.24,0.5,0.77)$ & $(0.36,0.61,0.83)$ & $(0.24,0.48,0.77)$ \\
$\mathbf{K}_{\mathbf{8}}$ & $(0.24,0.48,0.77)$ & $(0.33,0.59,0.83)$ & $(0.3,0.5,0.8)$ & $(0.330 .59,0.83)$ & $(0.24,0.48,0.77)$ \\
$\mathbf{K}_{\mathbf{9}}$ & $(0.42,0.680 .87)$ & $(0.42,0.68,0.87)$ & $(0.08,0.3,0.49)$ & $(0.35,0.63,0.87)$ & $(0.28,0.54,0.81)$ \\
$\mathbf{K}_{\mathbf{1 0}}$ & $(0.54,0.81,0.97)$ & $(0.18,0.4,0.63)$ & $(0.69,0.9,1)$ & $(0.59,0.87,1)$ & $(0.33,0.59,0.83)$ \\
\hline
\end{tabular}

4. Adım: Eşitlik 14 ve Eşitlik 15 yardımıyla bulanık negatif ideal çözüm değerleri bulunmuş ve Tablo 10 'da gösterilmiştir. 
Tablo 10. Bulanık negatif ideal çözüm değerleri

\begin{tabular}{lc}
\hline $\mathbf{K}_{\mathbf{1}}$ & $(0.32,0.58,0.84)$ \\
$\mathbf{K}_{\mathbf{2}}$ & $(0,0.03,0.17)$ \\
$\mathbf{K}_{\mathbf{3}}$ & $(0.17,0.39,0.62)$ \\
$\mathbf{K}_{\mathbf{4}}$ & $(0.35,0.63,0.9)$ \\
$\mathbf{K}_{\mathbf{5}}$ & $(0.33,0.57,0.77)$ \\
$\mathbf{K}_{\mathbf{6}}$ & $(0.39,0.65,0.9)$ \\
$\mathbf{K}_{\mathbf{7}}$ & $(0.24,0.48,0.77)$ \\
$\mathbf{K}_{\mathbf{8}}$ & $(0.24,0.48,0.77)$ \\
$\mathbf{K}_{\mathbf{9}}$ & $(0.08,0.26,0.49)$ \\
$\mathbf{K}_{\mathbf{1 0}}$ & $(0.18,0.4,0.63)$ \\
\hline
\end{tabular}

5. Adım: Ağırlıklı Öklid uzaklık değerleri (ED) Eşitlik 16 ve Eşitlik 17 yardımı ile, ağırlıklı Hamming uzaklık değerleri (HD) ise Eşitlik 18 ve Eşitlik 19 yardımı ile bulunmuş ve Tablo 11'de verilmiştir.

Tablo 11. ED ve HD uzaklık değerleri

\begin{tabular}{lllllllllll}
\hline & BTC & ETH & XRP & LTC & EOS & BCH & BNB & USDT & XLM & TRX \\
\hline ED & 2.16 & 2.11 & 2.12 & 1.91 & 1.84 & 1.62 & 1.53 & 0.69 & 1.90 & 1.42 \\
HD & 3.15 & 3.03 & 3.03 & 2.68 & 2.50 & 2.21 & 2.12 & 0.81 & 2.63 & 1.42 \\
\hline
\end{tabular}

6. Adım: Eşitlik 20, Eşitlik 21 ve Eşitlik 22 yardımıyla göreli önem matrisi elde edilmiş ve Tablo 12'de gösterilmiştir.

Tablo 12. Göreli önem matrisi

\begin{tabular}{ccccccccccc}
\hline & BTC & ETH & XRP & LTC & EOS & BCH & BNB & USDT & XLM & TRX \\
\hline BTC & 0 & 0.17 & 0.17 & 0.73 & 0.98 & 1.48 & 1.67 & 3.82 & 0.79 & 2.93 \\
ETH & -0.17 & 0 & -0.01 & 0.55 & 0.81 & 1.31 & 1.49 & 3.65 & 0.62 & 2.75 \\
XRP & -0.17 & 0.01 & 0 & 0.56 & 0.81 & 1.32 & 1.50 & 3.65 & 0.62 & 2.76 \\
LTC & -0.73 & -0.55 & -0.56 & 0 & 0.25 & 0.76 & 0.94 & 3.09 & 0.01 & 2.20 \\
EOS & -0.98 & -0.81 & -0.81 & -0.25 & 0 & 0.50 & 0.69 & 2.84 & -0.19 & 1.95 \\
BCH & -1.48 & -1.31 & -1.32 & -0.76 & -0.50 & 0 & 0.18 & 2.34 & -0.69 & 1.44 \\
BNB & -1.67 & -1.49 & -1.50 & -0.94 & -0.69 & -0.18 & 0 & 2.15 & -0.84 & 1.26 \\
USDT & -3.82 & -3.65 & -3.65 & -3.09 & -2.84 & -2.34 & -2.15 & 0 & -3.03 & -0.89 \\
XLM & -0.79 & -0.62 & -0.62 & -0.01 & 0.19 & 0.69 & 0.84 & 3.03 & 0 & 2.14 \\
TRX & -2.93 & -2.75 & -2.76 & -2.20 & -1.95 & -1.44 & -1.26 & 0.89 & -2.14 & 0 \\
\hline
\end{tabular}

7. Adım: Eşitlik 23 yardımıyla alternatiflerin skor değerleri hesaplanmış Tablo 13'te gösterilmiştir.

Tablo 13. Alternatiflerin skor değerleri

\begin{tabular}{ll}
\hline BTC & 12.73 \\
ETH & 10.99 \\
XRP & 11.07 \\
LTC & 5.42 \\
EOS & 2.94 \\
BCH & -2.09 \\
BNB & -3.93 \\
USDT & -25.47 \\
XLM & 4.87 \\
TRX & -16.54 \\
\hline
\end{tabular}


8. Adım: Tablo 13’te bulanık CODAS yöntemi ile hesaplama sonucunda alternatiflerin almış oldukları skor değerleri görülmektedir. Bu değerler büyükten küçüğe doğru sıralanarak alternatifler arasındaki sıralamaya ulaşılır. Buna göre, bulanık CODAS yöntemi sonucunda alternatifler $\mathrm{BTC}>\mathrm{XRP}>\mathrm{ETH}>\mathrm{LTC}>\mathrm{XLM}>\mathrm{EOS}>\mathrm{BCH}>\mathrm{BNB}>\mathrm{TRX}>\mathrm{USDT}$ şeklinde sıralanmıştır.

\section{Sonuç ve Öneriler}

Kripto para birimleri, özellikle son yıllarda teknoloji ve internet kullanımının yaygınlaşmasıyla birlikte sıklıkla kullanılmaya başlanmıştır. Kripto paraların, güvenlik altyapısı olarak kriptolojik altyapıyı kullanması, matematiksel denklemler şeklinde şifrelenmesi, dijital ve sanal ortamlarda kullanabilme özelliğine sahip olması, herhangi bir aracı kurumun güven sağlamasına ihtiyaç duymaması gibi avantajlarla kullanımı artan yatırım araçlarıdır (Güleç vd. 2018: 33).

Yatırımcıların, alternatif olarak yatırım yapabilecekleri kripto paraların değerlendirildiği bu çalışmada bulanık ÇKKV yöntemlerinden bulanık CODAS yöntemi kullanılmıştır. Çalışmada kullanılan kriterler belirlenirken karar vericiler ile görüşülmüş ve yatırım yapmayı etkileyebilecek 10 adet kriter belirlenmiştir. Yatırım alternatifi olarak ise en çok işlem gören 10 alternatif kripto para birimi çalışmaya dahil edilmiştir. Bulanık CODAS yöntemi ile değerlendirme sonucunda BTC ilk sırada yer alırken USDT son sırada yer almıştır. İlk ortaya çıkan kripto para birimi olması, en fazla işlem hacmine sahip olması ve yatırımcılar açısından tercih edilebilir olması gibi nedenlerle BTC ilk sırada yer almıştır.

Elde edilen değerlendirmeler sonrasında kripto paralara yatırım yapacak olan yatırımcılara kripto paraların merkezsiz olması, yatırım için daha fazla araştırma yapılması, söz konusu kripto paraların geçmiş dönemlerdeki hareketlerin izlenmesi tavsiyeleri ile yatırım için BTC önerilmiştir.

Gelişmeye açık ve hala kesin bilgiler içermeyen kripto paraları değerlendirmek için bulanık CODAS yöntemi dışında diğer ÇKKV yöntemleri de kullanılarak sonuçlar karşılaştırılabilir. Bu çalışmaya farklı kriterler ve alternatifler eklenerek çalışma tekrarlanabilir ve sonuçların nasıl değiştiği araştırılabilir.

\section{Kaynakça}

Akcan, M. M. (2018). Kripto para piyasalarında sürü davranışının ölçülmesi (Yayımlanmamış yüksek lisans tezi). Manisa Celal Bayar Üniversitesi, Manisa.

Alkış, A. (2018). İslam hukuku açısından Bitcoin ve kripto para. Kahramanmaraş Sütçü İmam Üniversitesi Iktisadi ve İdari Bilimler Fakültesi Dergisi, 8(2), 69-90.

Aslan, F. Pençe, İ., Şişeci Çeşmeli, M. ve Kalkan, A. (2018). Bitcoin'in Türkiye piyasasındaki değerinin yapak zekâ teknikleri ile tahmini. 5. Uluslararası Yönetim Bilişim Sistemleri Konferansi, Ankara Yıldırım Beyazıt Üniversitesi, Ankara.

Ateş, B. A. (2016). Kripto para birimleri, Bitcoin ve muhasebesi. Çankırı Karatekin Üniversitesi Sosyal Bilimler Enstitüsü Dergisi, 7(1), 349-366.

Atik, M., Köse, Y., Yılmaz, B. ve Sağlam, F. (2015). Kripto para: Bitcoin ve döviz kurları üzerine etkileri. Bartın Üniversitesi IIIBF Dergisi, 6(11), 247-261.

Baykal N. ve Beyan T. (2004), Bulanık mantık ilke ve temelleri. Ankara: Bıçaklar Kitabevi.

Boltürk, E. (2018). Pythagorean fuzzy CODAS and its application to supplier selection in a manufacturing firm. Journal of Enterprise Information Management, 31(4), 550-564.

Boltürk, E. ve Kahraman, C. (2018). Natural gas technology selection using pythagorean fuzzy CODAS. J. Lui, J. Lu, Y. Xu, L. Martinez, E.E. Kerre (Ed), Data Science and Knowledge 
Engineering for Sensing Decision Support içinde (ss.1034-1041). UK: World Scientific. doi.org/10.1142/9789813273238_0131

Ceylan, F., Ekinci, R., Tüzün, O. ve Kahyaoğlu, H. (2018). Kripto para piyasasında balonların tespiti: Bitcoin ve Ethereum örneği. BMIJ, 6(3), 263-274.

Chen, C. T. (2000). Extensions of the TOPSIS for group decision-making under fuzzy environment. Fuzzy Sets and Systems, 114(1), 1-9.

Chuen, D. L. K., Guo, L. ve Wang, Y. (2017). Cryptocurrency: A new investment opportunity?, The Journal of Alternative Investments, 20(3), 16-40.

Çarkacıoğlu, A. (2016). Kripto-Para Bitcoin, Sermaye Piyasası Kurulu Araştırma Dairesi Araştırma Raporu. http://www.spk.gov.tr/SiteApps/Yayin/YayinGoster/1130. (Erişim Tarihi: 08.05.2019).

Dahooie, J. H., Vanaki, A. S. ve Mohammadi, N. (2019). Choosing the appropriate system for cloud computing implementation by using the interval-valued intuitionistic fuzzy CODAS multi-attribute decision-making method (case study: Faculty of New Sciences and Technologies of Tehran University). IEEE Transactions on Engineering Management, 1-14.

Durdu, E. (2018). Kripto para birimi olarak Bitcoin ve ceza hukuku (Yayımlanmamış yüksek lisans tezi). Galatasaray Üniversitesi, İstanbul.

Genç, U. C., Ayberkin, D., Karaman, E. ve Özen, Ü. (2018). Analitik hiyerarşi prosesi kullanarak kripto para seçimindeki faktörlerin belirlenmesi. 5. Uluslararası Yönetim Bilişim Sistemleri Konferansı, Ankara Yıldırım Beyazıt Üniversitesi, Ankara.

Güleç, Ö. F., Çevik, E. ve Bahadır, N. (2018). Bitcoin ile finansal göstergeler arasındaki ilişkinin incelenmesi. Kırklareli Üniversitesi Iktisadi ve İdari Bilimler Fakültesi Dergisi, 7(2), 18-37.

https://coinmarketcap.com (Erişim Tarihi: 06.06.2019).

https://cryptocurrencyfacts.com/what-is-a-cryptocurrency-exchange (Erişim Tarihi: 01.06.2018).

https://tr.investing.com (Erişim Tarihi: 09.03.2019).

Karakaşoğlu, N. (2008). Bulanık çok kriterli karar verme yöntemleri ve uygulama (Yayımlanmamış yüksek lisans tezi). Pamukkale Üniversitesi, Denizli.

Kaufmann, A. ve Gupta, M. M. (1988). Fuzzy mathematical models in engineering and management science. North Holland: Elsevier Science Publishers.

Keshavarz Ghorabaee, M., Amiri, M., Zavadskas, E. K., Hooshmand, R. ve Antucheviciene, J. (2017). Fuzzy extension of the CODAS method for multi-criteria market segment evaluation. Journal of Business Economics and Management, 18(1), 1-19.

Keshavarz Ghorabaee, M., Zavadskas, E. K., Turskis, Z. ve Antucheviciene, J. (2016). A new combinative distance-based assessment (CODAS) method for multi-criteria decision-making. Economic Computation \& Economic Cybernetics Studies \& Research, 50(3), 25-44.

Kristoufek, L. (2013). Bitcoin meets Google trends and Wikipedia: quantifying the relationship between phenomena of the internet era. Scientific Reports, 3, 3415.

Lim, S. J. ve Masih, M. (2017). Exploring portfolio diversification opportunities in Islamic capital markets through bitcoin: evidence from MGARCH-DCC and wavelet approaches. https://mpra.ub.uni-muenchen.de/79752/1/MPRA_paper_ 79752.pdf (Erişim Tarihi: 08.07.2019).

Nakamato, S. (2008). Bitcoin: a peer-to-peer electronic cash system. http://bitcoin.org/bitcoin.pdf (Erişim Tarihi: 10.07.2019). 
Panchal, D., Chatterjee, P., Shukla, R. K., Choudhury, T. ve Tamosaitiene, J. (2017). Integrated fuzzy AHP-CODAS framework for maintenance decision in urea fertilizer industry. Economic Computation \& Economic Cybernetics Studies \& Research, 51(3), 179-196.

Polat, M. ve Akbıyık, A. (2019). Sosyal medya ve yatırım araçlarının değeri arasındaki ilişkinin incelenmesi: Bitcoin örneği. Akademik İncelemeler Dergisi, 14(1), 443-462.

Ram, A., Maroun, W. ve Garnett, R. (2016). Accounting for the bitcoin: accountability, neoliberalism and a correspondence analysis. Meditari Accountancy Research, 24(1), 2-35.

Şahin, E. E. ve Özkan, O. (2018). Asimetrik volatilitenin tahmini: kripto para Bitcoin uygulaması. Bilecik Şeyh Edebali Üniversitesi Sosyal Bilimler Enstitüsü Dergisi, 3(2), 240-247.

Turan, Z. (2018). Kripto paralar, Bitcoin, blockchain, petro gold, dijital para ve kullanım alanları. Ömer Halisdemir Üniversitesi İktisadi ve İdari Bilimler Fakültesi Dergisi, 11(3), 1-5.

Tüfek, B. Ü. (2017). Elektronik ödeme araçları ve geleceğin yaklaşımı kripto para (Yayımlanmamış yükssek lisans tezi). Bahçeşehir Üniversitesi, İstanbul.

Uygunoğlu, T. ve Ünal, O. (2005). Seyitömer uçucu külünün betonun basınç dayanımına etkisi üzerine bulanık mantık. Yapı Teknolojileri Elektronik Dergisi, 1, 13-20.

Yalçın, N. ve Yapıcı Pehlivan, N. (2019). Application of the fuzzy CODAS method based on fuzzy envelopes for hesitant fuzzy linguistic term sets: a case study o a personnel selection problem. Symmetry, 11(4), 493.

Yeni, F. B. ve Özçelik, G. (2019). Interval-valued atanassov intuitionistic fuzzy CODAS method for multi criteria group decision making problems. Group Decision and Negotiation, 28(2), 433-452.

Yıldırım, H. (2018). Günlük Bitcoin ile altın fiyatları arasındaki ilişkinin test edilmesi: 2012-2013 yılları arası Johansen eşbütünleşme testi. İnsan ve Toplum Bilimleri Araştırmaları Dergisi, 7(4), 2328-2343.

Zadeh, L.A. (1965). Fuzzy sets. Information and Control, 8, 338-353.

Zadeh, L.A. (1975). The concept of a linguistic variable and its application to approximate reasoning-I. Information Sciences, 8, 199-249.

Zimmermann H.J, (2001). Fuzzy set theory and its applications. Kluwer Academic Publishers.

ETIKK ve BİLIMSEL İLKELER SORUMLULUK BEYANI

$\mathrm{Bu}$ çalışmanın tüm hazırlanma süreçlerinde etik kurallara ve bilimsel atıf gösterme ilkelerine riayet edildiğini yazar(lar) beyan eder. Aksi bir durumun tespiti halinde Afyon Kocatepe Üniversitesi Sosyal Bilimler Dergisi'nin hiçbir sorumluluğu olmayıp, tüm sorumluluk makale yazarlarına aittir. 